\title{
Evaluation of Prevalence and Risk Factors for Postpartum Depression Using the Edinburgh Postpartum Depression Scale: A Cross-Sectional Analytic Study
}

\author{
Gaye KAHVECI'1, Bekir KAHVECI'2a, Hamza ASLANHAN'1, Pakize Gamze ERTEN BUCAKTEPE ${ }^{1}$ \\ Diyarbakir, Turkey
}

\section{ABSTRACT}

OBJECTIVE: To evaluate the prevalence and associated risk factors for postpartum depression using the Edinburgh Postpartum Depression Scale.

STUDY DESIGN: The population of this cross-sectional analytic study consisted of 311 women who were admitted to our hospital at 4-6 weeks after birth. The data were collected between April-June 2018 by applying a sociodemographic data form consisting of 44 questions and the Edinburgh Postpartum Depression Scale consisting of 10 questions. We used the Edinburgh Postpartum Depression Scale in the postpartum period to divide parturients into those with $(n=47)$ and without $(n=264)$ postpartum depression using a cut-off score of $\geq 13$. The primary outcome is the prevalence of postpartum depression, while the secondary outcomes are associated-risk factors.

RESULTS: The postpartum depression prevalence was $15.1 \%(n=47)$. In the postpartum depression group, the difference was highly significant in terms of abortion, antenatal depression, inadequate care for the baby, and health problem in the newborn $: 0.6 \pm 0.9$ vs. $0.2 \pm 0.6,13(37.1 \%)$ vs. $27(10.5 \%), 9$ $(56.3 \%)$ vs. $38(12.9 \%), 12(36.4 \%)$ vs. $35(12.6 \%)$, respectively* $(p<0.001)$. The Logistic regression analysis revealed that abortion by 1.64 fold $(1.13-2.37 \%$ at $95 \% \mathrm{Cl})$, antenatal depression by 5.04 fold $(2.38-10.68 \%$ at $95 \% \mathrm{Cl})$, inadequate baby care by 6.28 fold $(1.89-20.86 \%$ at $95 \% \mathrm{Cl})$, and health problem in the newborn by 3.59 fold $(1.43-8.99 \%$ at $95 \% \mathrm{Cl})$ increased postpartum depression.

CONCLUSION: postpartum depression is a health problem that can affect primarily mother and child. Therefore, it is important to determine highly predictable risk factors using a scale (e.g. Edinburgh Postpartum Depression Scale) for early diagnosis and timely treatment of symptoms.

Keywords: Edinburgh postpartum depression scale, Postpartum depression, Prevalence, Risk factors

Gynecol Obstet Reprod Med 2021;27(3):227-233

${ }^{1}$ Department of Family Medicine, Dicle University, Diyarbakir, Turkey

2 Department of Obstetrics and Gynecology, Cukurova University, Adana, Turkey (New institution)

a Department of Obstetrics and Gynecology, Health Sciences University, Gazi Yasargil Research and Training Hospital, Diyarbakir, Turkey (The old institution where I worked)

Address of Correspondence: Bekir Kahveci

University of Cukurova, School of Medicine,

Department of Obstetrics and Gynecology

01330 Adana, Turkey

drbekirkahveci@hotmail.com

Submitted for Publication: 29.05.2020 Revised for Publication: 13.10 .2020 Accepted for Publication: 07.11.2020 Online Published: 27.12.2020

ORCID IDs of the authors: $\quad$ GK:0000-0002-7492-0470

BK: 0000-0002-8729-1669, HA: 0000-0002-0904-3811

PGEB: 0000-0003-0544-4906

\begin{tabular}{|c|c|}
\hline \multirow{3}{*}{ 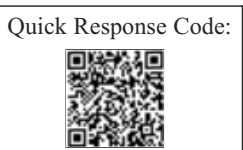 } & Access this article online \\
\hline & $\begin{array}{l}\text { Website: www.gorm.com.tr } \\
\text { e- mail: info@gorm.com.tr }\end{array}$ \\
\hline & DOI:10.21613/GORM.2020.1109 \\
\hline
\end{tabular}

How to cite this article: Kahveci G. Kahveci B. Aslanhan H. Erten Bucaktepe $P G$. Evaluation of Prevalence and Risk Factors for Postpartum Depression Using the Edinburgh Postpartum Depression Scale: A Cross-Sectional Analytic Study. Gynecol Obstet Reprod Med 2021;27(3):227-233

\section{Introduction}

Although pregnancy is part of the natural cycle of women's life, it may lead to an increase in anxiety and stress levels due to changes, especially physical and psychosocial. Because of this stress and anxiety, one in seven women is affected by mood disorders in the postpartum period (1). Postpartum depression (PPD) is the most common complication in the puerperium with a prevalence rate ranging from $10 \%$ to $28 \%$ in women. (2-4). Postpartum mood disorders are examined under three categories. These are postpartum blues, PPD, and postpartum psychosis (5). Years of research have identified some factors that increase a woman's risk of psychiatric disorders in the postpartum period. These factors can be listed as complications associated with a personal or family history of psychiatric illness, increased life stress, pregnancy, birth, breastfeeding, and neonatal health. Studies have shown that the key factor in the emergence of PPD is psychological stress. Although the onset of PPD has been most commonly observed in the first 4-6 weeks after birth, it may have a later 
onset. According to the diagnostic and statistical manual of mental disorders (DSM-V), PPD represents a period with major depressive symptoms that occurs within 4 weeks after birth and lasts at least 2 weeks (6).

Studies have shown that babies of depressed mothers are more likely to experience delays in both cognitive and social skills. Moreover, PPD additionally causes an increased burden on the healthcare system, reduced work efficiency, and a higher risk of chronic depression in the later period. The American College of Obstetricians and Gynecologists recommends that every woman be screened for PPD at least once in the perinatal period, using a standardized, validated method. A universal screening reduces the negative consequences of PPD by ensuring early recognition of symptoms and timely intervention. For this, the Edinburgh Postpartum Depression Scale (EPDS) has been validated and shows high reliability and sensitivity to detect postnatal depression (7).

In this study, we aimed to evaluate the prevalence and associated risk factors for PPD using the EPDS.

\section{Material and Method}

The population of this cross-sectional analytic study consisted of women who were admitted to the gynecology and obstetrics outpatient clinic of the University of Health Sciences, Diyarbakir Gazi Yasargil Training and Research Hospital after birth. The study was started after obtaining approval from the ethics committee (approval number: 87/date: 15.02.2018). The data were collected between April-June 2018 by applying a questionnaire to women who gave birth. Participation in the screening was entirely voluntary and free of charge. All women gave their written informed consent and the study was conducted in accordance with the Declaration of Helsinki.

The study inclusion criteria were as follows: admitting to the obstetrics outpatient clinic at 4-6 weeks after birth, being between the ages of 18-45 years, accepting to participate in the study, having a live birth. The exclusion criteria were as follows: mental disability or language disorder to prevent communication, being under the age of 18 and over 45 years, having a stillbirth, being a convicted patient, and refusing to participate in the study. The study included 311 women who met the participation criteria. We used the EPDS in the postpartum period to divide parturients into those with $(n=47)$ and without ( $n=264$ ) PPD using a cut-off score of $\geq 13$.

The dependent variables of the study were postpartum depression and the independent variables were the information included in the sociodemographic data questionnaire consisting of 44 questions. In the questionnaire, the age of the patients included in the study, husband's age, educational background, husband's educational background, job, social security status, family's economic status, place of residence (city center, district center, village-town) family type (extended family, small family), age at first marriage, age at first conception, gravida, parity, abortion, whether pregnancy is planned, whether pregnancy is intended, presence of antenatal and perinatal depression, comorbid disease, chronic medication use, type of delivery, how and with whom the decision of delivery type is made, type of health problem in the baby, couples' baby gender preference, satisfaction with the gender of the baby, the mother's adequate care for the baby, breastfeeding, problems and communication between the couples, adequate support of husband and family for the mother, father with psychiatric illness, the mother's relationship with her and her husband's family, number and adequacy of care received in the antenatal period were questioned.

The EPDS is a screening method used to determine the prevalence of PPD in women who gave birth (7). The EPDS is a 4-point Likert-type scale with a total of 10 items. These four items are scored between $0-3$. The items 1,2 , and 4 are scored as $0,1,2,3$ points, while other items are scored as 3 , $2,1,0$ points. The lowest score that can be obtained from the EPDS is 0, while the highest score is 30 . The correlation between the EPDS and the General Health Questionnaire was found as $\mathrm{r}: 0.7(p<0.001)$ and the validity was accepted. Because studies stating that women scoring $\geq 13$ points from the EPDS are at risk for PPD are predominant, the cut-off point was taken as $\geq 13$ (8).

\section{Statistical analysis}

The power analysis in the study was calculated with the "This Sample Size Calculator Software" (http://www.surveysystem.com/sscalc.htm) prepared by the "The Survey System" so as the sample volume to be $80 \%$. The statistical analyses were performed using the SPSS (Statistical Package for Social Sciences) version 25.0 software. The data were shown as mean \pm standard deviation (mean $\pm \mathrm{SD})$, number $(\%)$, and the results of the logistic regression analysis were shown as estimated relative risk (odds ratio-OR) and 95\% confidence interval (CI). In the intergroup evaluation, the Chi-square analysis was used for categorical data. The Mann-Whitney U test was used for the correlation analysis of non-parametric data. While a $p$-value of $<0.05$ was considered significant in the evaluation, a $p$-value of $<0.001$ was considered highly significant.

\section{Results}

A total of 311 women participated in the study; of these, $47(15.1 \%)$ scored $\geq 13$ points and $264(84.9 \%)$ scored $<13$ points on the EPDS (Table I). The mean age of the women was $27.5 \pm 5.9$ years, the mean gravida was $3.1 \pm 2$, the mean parity was $2.6 \pm 1.6$, the mean number of abortion was $0.3 \pm 0.7$. While the mean number of abortions was $0.6 \pm 0.9$ in the PPD $(+)$ group, the mean number of abortions was $0.2 \pm 0.6$ in the PPD (-) group $(p<0.001)$ (Table II). 
Table I: Depression score levels of patients according to Edinburgh Postpartum Depression Scalea

\begin{tabular}{lccc}
\hline Depression scores & $\mathrm{n}=311$ & $(\%)$ \\
\hline$\geq 13$ & 47 & 15.1 & 84.9 \\
$<13$ & 311 & 264 & 100 \\
Total & 311 & \\
\hline
\end{tabular}

${ }^{a}$ Data are presented as number (percentage).

Table II. Demographic data of patients with and without postpartum depression

\begin{tabular}{|c|c|c|c|c|}
\hline Variables & Total & $\begin{array}{l}\text { PPD (+) } \\
\text { EPDS } \geq 13\end{array}$ & $\begin{array}{l}\text { PPD (-) } \\
\text { EPDS }<13\end{array}$ & $p$ \\
\hline $\mathrm{Age}^{\mathrm{a}}$ & $27.5 \pm 5.9$ & $29 \pm 6.3$ & $27 \pm 5.8$ & 0.005 \\
\hline Husband's age & $30 \pm 6.2$ & $32 \pm 6.7$ & $29 \pm 6.0$ & 0.009 \\
\hline Age at first marriage ${ }^{a}$ & $21 \pm 4.1$ & $20 \pm 4.2$ & $21 \pm 4.0$ & 0.351 \\
\hline Age at first conceptiona & $22 \pm 4.3$ & $21 \pm 4.0$ & $22 \pm 4.1$ & 0.272 \\
\hline Gravida $^{a}$ & $3.1 \pm 2$ & $4 \pm 2.3$ & $3 \pm 1.9$ & 0.009 \\
\hline Abortiona & $0.3 \pm 0.7$ & $0.6 \pm 0.9$ & $0.2 \pm 0.6$ & $<0.001^{*}$ \\
\hline Paritya & $2.6 \pm 1.6$ & $3 \pm 2$ & $2 \pm 1.5$ & 0.055 \\
\hline \multicolumn{5}{|l|}{ Place of residence ${ }^{b}$} \\
\hline City center & $114(36.7)$ & $20(42.6)$ & $94(35.6)$ & \\
\hline District center & $105(33.8)$ & $16(34.0)$ & $89(33.7)$ & 0.538 \\
\hline Village-town & $92(29.6)$ & $11(23.4)$ & $81(30.7)$ & \\
\hline \multicolumn{5}{|l|}{ Jobb } \\
\hline Working & $10(3.2)$ & $2(4.3)$ & $8(3.0)$ & 0.651 \\
\hline Not working & $301(96.8)$ & $45(95.7)$ & $256(97.0)$ & \\
\hline \multicolumn{5}{|l|}{ Family typeb } \\
\hline Extended family & $120(38.6)$ & $15(31.9)$ & $105(39.8)$ & 0.334 \\
\hline Small family & $191(61.4)$ & $32(68)$. & $159(60.2)$ & \\
\hline
\end{tabular}

EPDS: Edinburgh Postpartum Depression Scale, PPD: Postpartum depression, a: Data are given as mean \pm standard deviation. b: Data are presented as number (percentage). ${ }^{*} p<0.001$ : Statistically high significance, $p<0.05$ : Statistically significant

Of the women, $213(68.5 \%)$ planned their pregnancies. Of the infants, $33(10.6 \%)$ had a health problem. The most common health problems were elevated bilirubin, VSD (Ventricular Septal Defect), transient tachypnea of the newborn. $16(5.1 \%)$ of the patients stated that they could not provide adequate care to their babies, and $11(3.5 \%)$ of these were being followed up in the neonatal intensive care unit.

Of the women, $24(11.3 \%)$ with planned pregnancy had PPD, while 23 (23.5\%) with unplanned pregnancy had PPD; 13 (37.1\%) who experienced antenatal depression had PPD, while $34(12.3 \%)$ who did not experience antenatal depression had PPD; 20 (37\%) who experienced perinatal depression had PPD, while $27(10.5 \%)$ who did not experience perinatal depression had PPD $(p<0.001) ; 19(10.9 \%)$ who had normal vaginal delivery had PPD, while $28(20.4 \%)$ who delivered by cesarean section had PPD, 6 (6.3\%) who desired female gender had PPD, while 78 (21.8\%) who desired male gender had PPD, 38 (12\%) who breastfed had PPD, while 10 (40\%) who did not breastfeed had PPD; 38 (12\%) who provided adequate care for the baby had PPD, while $9(56.3 \%)$ who did not provide adequate care for the baby had PPD $(p<0.001) ; 38$
(13.2\%) who had good communication with her husband had PPD, while 9 (37.5\%) who did not have good communication with her husband had PPD; 37 (12.9\%) who thought that they received sufficient care from her husband and family had PPD, while 10 (40\%) who did not think they received sufficient care had PPD; 27 (11.9\%) with moderate-good economic status had PPD, while $20(24.1 \%)$ with poor economic status had PPD; 36 (18\%) whose delivery type was decided by the healthcare providers had PPD, while $11(9.7 \%)$ whose delivery type was not decided by the healthcare providers had PPD; $12(36.4 \%)$ with health problems in the newborn had PPD, while $35(12.6 \%)$ without health problems in the newborn had PPD $(p<0.001)$ (Table III).

The Logistic regression analysis revealed that abortion by 1.64 fold $(1.13-2.37 \%$ at $95 \% \mathrm{CI})$, antenatal depression by 5.04 fold $(2.38-10.68 \%$ at $95 \% \mathrm{CI})$, inadequate baby care by 6.28 fold $(1.89-20.86 \%$ at $95 \% \mathrm{CI})$, and health problem in the newborn by 3.59 fold $(1.43-8.99 \%$ at $95 \% \mathrm{CI})$ increased PPD (Table IV). It was determined that the logistic regression model created can predict women who are at risk of PPD with a rate of $86.5 \%$. 
Table III: Risk factors that are significant as a result of postpartum depression screening with Edinburgh Postpartum Depression Scalea

\begin{tabular}{|c|c|c|c|}
\hline Variables & $\begin{array}{c}\text { PPD }(+) \\
\text { EPDS } \geq 13\end{array}$ & $\begin{array}{c}\text { PPD }(-) \\
\text { EPDS }<13\end{array}$ & $p$ \\
\hline \multicolumn{4}{|c|}{ Plan status of pregnancy } \\
\hline Planned pregnancy & $24(11.3)$ & $189(88.7)$ & 0.010 \\
\hline Unplanned pregnancy & $23(23.5)$ & $75(76.5)$ & \\
\hline \multicolumn{4}{|c|}{ Depression before pregnancy } \\
\hline Yes & $13(37.1)$ & $22(62.9)$ & 0.001 \\
\hline No & $34(12.3)$ & $242(87.7)$ & \\
\hline \multicolumn{4}{|l|}{ Antenatal depression } \\
\hline Yes & $20(37)$ & $34(63)$ & $<0.001^{*}$ \\
\hline No & $27(10.5)$ & $230(89.5)$ & \\
\hline \multicolumn{4}{|l|}{ Methods of delivery } \\
\hline VD & $19(10.9)$ & $155(89.1)$ & 0.025 \\
\hline$C D$ & $28(20.4)$ & $109(79.6)$ & \\
\hline \multicolumn{4}{|c|}{ Infant gender preference } \\
\hline Female & $6(6.3)$ & $90(93.7)$ & 0.029 \\
\hline Male & $78(21.8)$ & $61(78.2)$ & \\
\hline No preference & $24(17.5)$ & $113(82.5)$ & \\
\hline \multicolumn{4}{|l|}{ Breastfeeding } \\
\hline Yes & $37(12.9)$ & $249(87.1)$ & 0.001 \\
\hline No & $10(40)$ & $159(60)$ & \\
\hline \multicolumn{4}{|c|}{ Adequate care for the baby } \\
\hline Yes & $38(12.9)$ & $257(87.1)$ & $<0.001^{*}$ \\
\hline No & $9(56.3)$ & $7(43.7)$ & \\
\hline \multicolumn{4}{|c|}{ Communication between couples } \\
\hline Yes & $38(13.2)$ & $249(86.8)$ & 0.004 \\
\hline No & $9(37.5)$ & $15(62.5)$ & \\
\hline \multicolumn{4}{|c|}{ Adequate support from husband and family } \\
\hline Yes & $37(12.9)$ & $249(87.1)$ & 0.001 \\
\hline No & $10(40)$ & $15(60)$ & \\
\hline \multicolumn{4}{|l|}{ Economic status } \\
\hline Bad & $20(24.1)$ & $63(75.9)$ & 0.008 \\
\hline Mid-good & $27(11.9)$ & $201(88.1)$ & \\
\hline \multicolumn{4}{|c|}{ Decision of delivery method } \\
\hline Sanitarian & $36(18.2)$ & $162(81.8)$ & 0.045 \\
\hline Other & $11(9.7)$ & $102(90.3)$ & \\
\hline \multicolumn{4}{|c|}{ Health problem in the newborn } \\
\hline Yes & $12(36.4)$ & $21(63.6)$ & $<0.001^{*}$ \\
\hline No & $35(12.6)$ & $243(87.4)$ & \\
\hline Total (n: 311) & $47(15.1)$ & 264 (84.9) & \\
\hline
\end{tabular}

PPD: Postpartum depression, EPDS: Edinburgh Postpartum Depression Scale, VD: Vaginal delivery, CD: Cesarean delivery. a: Data are presented as number (percentage). ${ }^{*} p<0.001$ : Statistically high significance, $p<0.05$ : Statistically significant.

Table IV: Results of logistic regression analysis with postpartum depression

\begin{tabular}{lcccccr}
\hline Predictors & Wald 2 & df & $p$ & Odds ratio & $\begin{array}{r}\text { Lower } \\
95 \% \mathrm{Cl}\end{array}$ & $\begin{array}{r}\text { Higher } \\
95 \% \mathrm{Cl}\end{array}$ \\
\hline Abortion & & & & 1.64 & 1.13 & 2.37 \\
Antenatal depression & 6.77 & 1 & 0.009 & 5.04 & 2.38 & 10.68 \\
Inadequate care for the baby & 17.92 & 1 & 0.000 & 6.28 & 1.89 & 20.86 \\
Health problem in the newborn & 9.02 & 1 & 0.003 & 3.59 & 1.43 & 8.99 \\
\hline
\end{tabular}

Cl: Confidence interval 


\section{Discussion}

Considering its effects on mother and child, PPD is a public health problem that should be attached to importance. Due to the health problems caused by PPD in mother and child, studies on its prevalence and causes in communities are the most important steps to be taken in the prevention of the disease.

The prevalence of PPD was found as $23.8 \%$ in a metaanalysis conducted in Turkey (3), while in another study conducted to verify the Turkish form of EPDS, it was found as $14.4 \%$ (9). In a comprehensive meta-analysis including 59 studies, the prevalence of PPD was found as $13 \%$ (2). The review study by Halbreich et al. (10) including the results of 143 studies from 40 countries found the prevalence of PPD as 10$15 \%$. The reasons for the difference in rates found by these studies can be explained as follows: 1-The differences in the diagnostic tools and study methods used to detect the prevalence of PPD are notable; 2-Participants were included in the studies at different periods in the postpartum period; and 3The presence of heterogeneous groups including different centers, different cultures, and different risk groups also causes differences. However, researchers attribute the low prevalence of PPD in some cultures to cultural support factors (11). We found the prevalence of PPD, the primary outcome of our study, as $15.1 \%$.

The prevalence of PPD varies depending on the depression scale used in the studies and the group to which it is applied. In postpartum samples, the sensitivity and the specificity of the EPDS have been found as $86 \%$ and $76 \%$, respectively. It has been reported that the EPDS accurately measures depressive symptoms in antenatal and postpartum periods. EPDS is not a diagnostic scale and is used for symptom screening. The diagnosis should be confirmed by clinical examination and diagnostic scales.

Given the relationship between PPD and age, there are contradictory results in the literature. For example, studies are reporting that the young age of mother increases $(12,13)$, decreases (14) or is not associated with (15) the risk of PPD. It is known that the risk of PPD is high in adolescent mothers (16). The women who participated in our study were not adolescents and the mean age was significantly higher in the PPD $(+)$ group.

Studies have shown that there is a small but significant relationship between PPD and low-income level, financial tension, unemployed mother, and low social status (2). In a 2017 meta-analysis including 52 studies, the economic status and the employment status of the husband came to the fore among the factors associated with PPD development (3). Another study found that PPD was 1.8 fold higher in mothers without income in reference to mothers with income (17). As a result, the low-income level was determined as a socioeconomic risk factor for postpartum depression $(18,19)$. In our study, there was a significant correlation between economic status and the prevalence of PPD.

There are different results regarding the effect of the parity on PPD. While the study by Palumbo et al. (18) conducted in 2017 showed that the parity was not associated with PPD, a review conducted in communities of Asian culture reported that having too many children in countries with economic distress increased the prevalence of PPD as it would create an economic and psychological difficulty. In the case-control study by Josefsson et al. conducted in Sweden (20), it was reported that the number of births did not affect PPD. In our study, the difference between parity and PPD was not significant.

In a review, it was found that the presence of a history of abortion-stillbirth increased the prevalence of PPD in 6 of 15 studies (3). Another study included having 2 or more miscarriages in the factors that increase PPD (21). In our study, it was found that the number of abortions increased PPD by 1.64 fold. Thus, abortion due to any reason creates stress on mothers.

Unintended or unplanned pregnancy is also a risk factor for the development of PPD (18,22). Arslantaş et al. (23) stated that the intended pregnancy significantly decreased the prevalence of PPD. Our study is consistent with the literature and it can be predicted that evaluating whether the pregnancy is intended, protection of the woman against unintended pregnancies will be effective in decreasing the prevalence of PPD. Therefore, family planning services should be provided to all couples.

Having any health problems during pregnancy also increases the risk of PPD. In the study by Inandi et al. (19), it was reported that having a health problem during pregnancy caused 1.6 fold more PPD. In the present study, antenatal depression increased PPD by 5.04 fold.

When evaluated in terms of delivery type, some cohort studies show that PPD is not associated with the type of delivery, but the severity of pain experienced during and after delivery (24). The study by Patel et al. (25) including 10,934 women showed that the type of delivery did not affect PPD. Although there are contradictory results in the literature in this regard, PPD was more common after cesarean delivery in our study. We think that cesarean delivery is a cause of stress in patients due to being an operation and postoperative complications experienced.

Breastfeeding has numerous health benefits for both mother and baby. Therefore, the World Health Organization recommends only breast milk for the first 6 months. Despite studies reporting a significant relationship between breastfeeding and PPD development $(24,26)$, there are also studies that found no relationship (18). It has been found that patients with PPD have more difficulties in breastfeeding, insensible attitudes towards breastfeeding, and early cessation of breast- 
feeding (27). Our study is consistent with the literature and breastfeeding is of great importance for both maternal and baby health.

It has been shown that the presence of newborn complications in the baby triggers the development of PPD in the mother. Babies having health problems increase the stress on mothers, which may increase the risk of depression (28). In our study, the presence of a health problem in the baby increased PPD by 3.59 fold.

The effect of the gender of the baby on PPD varies between communities. While a study conducted in Sweden found that the gender of the baby was not associated with PPD (28), a study conducted in China showed that having a baby girl was associated with PPD (29). Özdemir et al. (30) found a significant relationship between mothers who had a change in the attitude of her husband and/or her husband's family and PPD as a result of knowing the baby's gender. Our study found that those who desired to have a boy but had a girl had a risk for PPD. We attribute this to the higher value given to boys in some regions of our country.

A history of psychiatric illness is a risk factor for the development of PPD in many developed and developing countries (31). In a meta-analysis including 59 studies, previous psychiatric or psychological problems were considered the prominent precursors of depression within a few months after birth (2). Regarding that, the DSM-V states that $50 \%$ of postpartum depression periods actually start before birth and collectively characterize these periods as "peripartum period" (6). In the present study, antenatal depression was found to increase PPD by 5.04 fold.

Family problems experienced in this period when the woman tries to adapt to her baby and new living conditions, make adaptation to the postpartum period difficult. Gümüş et al. (32) found the EPDS scores of those who have negative relationships with the husband and those who do not receive family support to be significantly higher. Marriage problems, absence of husband support, unhappiness in marriage, poor communication with husband and family of the husband have been indicated in many studies as a risk factor for PPD $(33,34)$. In our study, the prevalence of PPD was found to be lower in those who have good communication with her husband and in the women who thought that they received sufficient care from their families. Studies have shown that the risk of developing PPD increases in individuals who cannot establish good relationships with her husband and families, and who cannot receive social support from them.

In conclusion, we demonstrated the prevalence of PPD and some associated risk factors using the EPDS. Postpartum depression is a serious problem that affects many mothers and babies. Therefore, it is important to closely monitor the emotional changes of the mother and to determine the highly pre- dictable risk factors using a scale, such as the EPDS, for early diagnosis and timely treatment of symptoms.

Acknowledgments: This study did not receive any specific grant from any funding agency in the public, commercial, or not-for-profit sector. Presented as an oral presentation at the 19th International Eastern Mediterranean Family Medicine Congress (17-20 September 2020, Adana, Turkey).

Funding: None

Author contribution: GK: Writing, surgical and medical practice, design, data collection, analysis or interpretation, literature search, BK: Writing, surgical and medical practice, design, data collection, analysis or interpretation, literature search, HA: Design, analysis or interpretation, PGEB: Data collection

Conflict of interest statement : The authors declare that there are no conflicts of interest.

\section{References}

1. Shelton LS, Cormier E. Depressive symptoms and influencing factors in low-risk mothers. Issues Ment Health Nurs. 2018;39(3):251-8. Doi: 10.1080/01612840.2017.14 04170 .

2. O'Hara MW, Swain AM. Rates and risk of postpartum depression a meta-analysis. Int Rev Psychiatry. 1996;8(1): 37-54. Doi: 095pO261/96/010037-18.

3. Ozcan NK, Boyacioglu NE, Dinc H. Postpartum depression prevalence and risk factors in Turkey: A systematic review and meta-analysis. Arch Psychiatr Nurs. 2017;31 (4):420-8. Doi: 10.1016/j.apnu.2017.04.006.

4. Roomruangwong C, Withayavanitchai S, Maes M. Antenatal and postnatal risk factors of postpartum depression symptoms in Thai women: a case-control study. Sex Reprod Health. 2006;10:25-31. Doi: 10.1016/j.srhc.2016. 03.001 .

5. Gulseren L. Doğum sonrası depresyon: Bir gözden geçirme. Türk Psikiyatri Derg. 1999;10(1):58-67.

6. 35. Association AP. Diagnostic and statistical manual of mental disorders (DSM-5). $5^{\text {th }}$ ed. London: American Psychiatric Pub; 2013. p. 317-391.

7. Cox JL, Holden JM, Sagovsky R. Detection of postnatal depression: development of the 10-item Edinburgh Postnatal Depression Scale. Br J Psychiatry. 1987;150: 782-6. Doi: 10.1192/bjp.150.6.782.

8. Erdem O, Bucaktepe PGE. Postpartum depresyon görülme Sıklığı ve tarama yöntemleri. Dicle Tıp Derg. 2012;39 (3):458-61. Doi:10.5798/diclemedj.0921.2012.03.018 2.

9. Aydin N, Inandi T, Yigit A, Hodoglugil NN. Validation of the Turkish version of the Edinburgh Postnatal Depression Scale among women within their first postpartum year. Soc Psychiatry Psychiatr Epidemiol. 2004:39(6):483-6. Doi: 10.1007/s00127-004-0770-4.

10. Halbreich U, Karkun S. Cross-cultural and social diversity 
of prevalence of postpartum depression and depressive symptoms. J Affect Disord. 2006;91(2-3):97-111. Doi: 10. 1016/j.jad.2005.12.051.

11. Bina R. The impact of cultural factors upon postpartum depression: a literature review. Health Care Women Int. 2008;29(6):568-92. Doi: org/10.1080/073993308020891 49.

12. Kozinszky Z, Dudas RB, Csatordai S, Devosa I, Tóth É, Szabó D, et al. Social dynamics of postpartum depression: a population-based screening in South-Eastern Hungary. Soc Psychiatry Psychiatr Epidemiol. 2011;46(5):413-23. Doi: 10.1007/s00127-010-0206-2.

13. Quelopana AM, Champion JD, Reyes-Rubilar T. Factors associated with postpartum depression in Chilean women. Health Care Women Int. 2011;32(10):939-49. Doi: 10.10 80/07399332.2011.603866.

14. Glavin K, Smith L, Sørum R. Prevalence of postpartum depression in two municipalities in Norway. Scand J Caring Sci. 2009;23(4):705-10. Doi: 10.1111/j.1471-67 12.2008.00667.x.

15. Green K, Broome H, Mirabella J. Postnatal depression among mothers in the United Arab Emirates: socio-cultural and physical factors. Psychol Health Med. 2006;11 (4):425-31. Doi: 10.1080/13548500600678164.

16. Reid V, Meadows-Oliver M. Postpartum depression in adolescent mothers: an integrative review of the literature. J Pediatr Health Care. 2007;21(5):289-98. Doi: 10.1016/j. pedhc.2006.05.010.

17. Sütlü S. Burdur ilinde lohusalarda postpartum depresyon prevalansı ve etki eden faktörler. Isparta, Süleyman Demirel Üniversitesi Sağlık Bilimleri Enstitüsü, Halk Sağlığı Uzmanlık Tezi, 2016.

18. Palumbo G, Mirabella F, Gigantesco A. Positive screening and risk factors for postpartum depression. Eur Psychiatry. 2017;42:77-85. Doi: 10.1016/j.eurpsy. 2016.11.009.

19. Inandi T, Elci OC, Ozturk A, Egri M, Polat A, Sahin TK. Risk factors for depression in postnatal first year, in eastern Turkey. Int J Epidemiol. 2002;31(6):1201-7. Doi: 10.1093/ije/31.6.1201.

20. Josefsson A, Angelsiöö L, Berg G, Ekström CM, Gunnervik C, Nordin C, et al. Obstetric, somatic, and demographic risk factors for postpartum depressive symptoms. Obstet Gynecol. 2002;99(2):223-8. Doi: 10.1016/s 0029-7844(01)01722-7.

21. Lee DT, Yip AS, Chiu HF, Chung TK. Screening for postnatal depression using the double-test strategy. Psychosom Med. 2000;62(2):258-63. Doi: 10.1097/0000 6842-200003000-00018.

22. Brito CN, Alves SV, Ludermir AB, Araújo TV. Postpartum depression among women with unintended preg- nancy. Rev Saude Publica. 2015;49:33. Doi: 10.1590/ s0034-8910.2015049005257.

23. Arslantaş H, Ergin F, Balkaya NA. Aydın il merkezinde doğum sonrası depresyon sıklığı ve ilişkili risk etmenleri. ADÜ Tıp Fakültesi Derg. 2009;10(3):13-22.

24. Gaillard A, Le Strat Y, Mandelbrot L, Keïta H, Dubertret C. Predictors of postpartum depression: prospective study of 264 women followed during pregnancy and postpartum. Psychiatry Res. 2014;215(2):341-6. Doi: 10.1016/j. psychres.2013.10.003.

25. Patel RR, Murphy DJ, Peters TJ. Operative delivery and postnatal depression: a cohort study. BMJ. 2005;330 (7496):879. Doi: 10.1136/bmj. 38376.603426.D3.

26. Nakku JE, Nakasi G, Mirembe F. Postpartum major depression at six weeks in primary health care: prevalence and associated factors. Afr Health Sci. 2006;6(4):207-14. Doi: 10.5555/afhs.2006.6.4.207.

27. Dunn S, Davies B, McCleary L, Edwards N, Gaboury I. The relationship between vulnerability factors and breastfeeding outcome. J Obstet Gynecol Neonatal Nurs. 2006;35(1):87-97. Doi: 10.1111/j.1552-6909.2006.000 05.x.

28. Sylven SM, Thomopoulos TP, Kollia N, Jonsson M, Skalkidou A. Correlates of postpartum depression in first time mothers without previous psychiatric contact. Eur Psychiatry. 2017;40:4-12. Doi: 10.1016/j.eurpsy.2016.07. 003.

29. Deng AW, Xiong RB, Jiang TT, Luo YP, Chen WZ. Prevalence and risk factors of postpartum depression in a population-based sample of women in Tangxia Community, Guangzhou. Asian Pac J Trop Med. 2014;7(3): 244-9. Doi: 10.1016/S1995-7645(14)60030-4.

30. Ozdemir S, Marakoğlu K, Civi S. Konya il merkezinde dogum sonrası depresyon riski ve etkileyen faktörler. TAF Prev Med Bull. 2008;7(5):391-8.

31. Norhayati MN, Hazlina NH, Asrenee AR, Emilin WM. Magnitude and risk factors for postpartum symptoms: a literature review. J Affect Disord. 2015;175:34-52. Doi: 10.1016/j.jad.2014.12.041.

32. Gümüş AB, Keskin G, Alp N, Özyar S, Karsak A. Postpartum depresyon yaygınlığ 1 ve ilişkili değiş̧kenler. New/Yeni Symposium Journal. 2012;50(3):145-54.

33. Boyce PM. Risk factors for postnatal depression: a review and risk factors in Australian populations. Arch Womens Ment Health. 2003;6 Suppl 2:S43-50. Doi: 10.1007/ s00737-003-0005-9.

34. Mallikarjun PK, Oyebode F. Prevention of postnatal depression. J R Soc Promot Health. 2005;125(5):221-6. Doi: 10.1177/146642400512500514. 